\title{
Comparison of four endoluminal radiofrequency ablation devices and four power generators in an ex vivo bovine liver model
}

\author{
STEPHAN RHEINHEIMER ${ }^{1}$, ANNA JACOBSEN $^{2}$, PHILIPP MAYER $^{1}$, \\ HANS-ULRICH KAUCZOR $^{1}$ and ANDREAS HORST MAHNKEN ${ }^{3}$ \\ ${ }^{1}$ Department of Diagnostic and Interventional Radiology, University Hospital of Heidelberg, D-69120 Heidelberg; \\ ${ }^{2}$ Department of Neurosurgery, University Hospital of Schleswig-Holstein, D-23538 Lübeck; \\ ${ }^{3}$ Department of Diagnostic and Interventional Radiology, Philipps University of Marburg, D-35043 Marburg, Germany
}

Received May 12, 2021; Accepted September 13, 2021

DOI: $10.3892 /$ wasj.2021.128

\begin{abstract}
The aim of the present study was to investigate the ex vivo results of four different endoluminal bipolar radiofrequency ablation (RFA) probes at different energy settings and using four different power generators. Ex vivo RFA was performed on bovine liver using four different bipolar RFA probes: i) Habib ${ }^{\mathrm{TM}}$ EndoHPB (EMcision); ii) Habib ${ }^{\mathrm{TM}}$ VesOpen (EMcision); iii) Celon ProCurve micro 300-C09 (Olympus Corporation); and iv) Celon ProCurve 1200 S15 (Olympus Corporation). The following generators were also used: Erbe Vio 300D, KLS Martin Maxium, Olympus CelonPOWER and Boston RF3000. Overall, 430 ablations were carried out. The results revealed significant differences in the size of the achieved lesions and the duration of ablation $(\mathrm{P}<0.05)$ between the four different ablation devices. The maximum lesion diameters achieved with the devises were as follows: HabibTM EndoHPB, 13 watts (W; mean \pm standard deviation, 10.3 $\pm 1.8 \mathrm{~mm})$; Habib $^{\mathrm{TM}}$ VesOpen, $12 \mathrm{~W}(11.3 \pm 0.6)$; Celon ProCurve micro, $2 \mathrm{~W}$ (7.9 \pm 2.2$)$; and Celon ProCurve 1200, $10 \mathrm{~W}(9.2 \pm 1.1)$. The maximum lesion diameters induced by the various generators differed significantly. On the whole, the present study demonstrates that lesion size and ideal power settings vary between different endoluminal ablation devices and generators. The combination of the probe and generator should not be varied in clinical practice to ensure reliable results.
\end{abstract}

\section{Introduction}

In malignant biliary obstruction, local tumor control is mandatory to alleviate symptoms of jaundice, obtain a good quality

Correspondence to: Dr Stephan Rheinheimer, Department of Diagnostic and Interventional Radiology, University Hospital of Heidelberg, Im Neuenheimer Feld 420, D-69120 Heidelberg, Germany E-mail: Stephan.Rheinheimer@med.uni-heidelberg.de

Key words: radiofrequency ablation, endoluminal, biliary, tumor, radiofrequency, generator of life and prolong patient survival (1). Various endoluminal techniques to relieve biliary obstruction, such as percutaneous drainage, (resorbable) stents, photodynamic therapy and radiofrequency ablation (RFA) are available. There are a variety of RFA devices available on the market (2). RFA is still only rarely performed, potentially due to economic reasons, but also due to inexperience with this technique. Several studies, however, have indicated that this technique may represent an important addition to palliative stent placement. Within certain patient groups, studies have provided promising data on endobiliary RFA for malignant bile duct obstruction. A beneficial effect on the stent patency rate and survival rate may be achieved with the use of RFA (3-12). In a previous retrospective study by Strand et al (3), patients with unresectable cholangiocarcinoma exhibited a lower stent replacement rate and no significant difference in survival was observed following endoluminal RFA when compared with photodynamic therapy. Furthermore, certain studies have reported encouraging results for the treatment of vascular tumor thrombi (13), intrabronchial tumors (14) and urogenital tumors (15) by endoluminal RFA. Both endoscopic and percutaneous approaches are feasible (16). Stenting with a bare metal stent is usually recommended following the ablation of tumors of the bile duct.

The local availability of RFA generators and catheters may vary; thus, knowledge of the technical behavior of the respective devices is mandatory. To the best of our knowledge, to date, there are no comparative data available on the efficacy of various flexible endoluminal bipolar RFA probes and different power generators.

Hence, the present study aimed to compare coagulation zones in bovine liver tissue following intraluminal biliary RFA using four different electrodes and four different power generators.

\section{Materials and methods}

Probes. Habib ${ }^{\mathrm{TM}}$ EndoHPB (EMcision) is one of two Food and Drug Administration (FDA)-approved catheters for use in intraluminal bile duct ablation. The alternative probe ELRATM with four electrodes is a recently introduced device that was not investigated in the present study. Smaller devices 
for endovascular ablation are the Habib ${ }^{\mathrm{TM}}$ VesOpen (EMcision) and probes originally designed for varicosis, provided by Celon (Olympus Corporation).

Comparison of RFA probes. In the present study, four different RFA probes were used: i) Habib ${ }^{\mathrm{TM}}$ EndoHPB (EMcision); ii) $\mathrm{Habib}^{\mathrm{TM}}$ VesOpen (EMcision); iii) Celon ProCurve micro 300-C09 (Olympus Corporation); and iv) Celon ProCurve 1200 S15 (Olympus Corporation) (Fig. 1 and Table I).

Similar to the approach described in the study by Itoi et al (17), the probes were placed in bovine liver tissue at $22^{\circ} \mathrm{C}$, whilst avoiding large vessels. To avoid the bending of or damage to the electrodes, the liver capsule was incised at the puncture site. The fragile electrodes were then placed through a plastic tube which was pulled back as soon as the target position was reached. Care was taken to place the whole tip of the electrode in parenchyma without adjacent large vessels and with sufficient distance to the liver surface. Freshly excised bovine liver was obtained from the food sector. Therefore, no ethics approval was required.

Due to the design of the connectors, the power supply to the probes was provided by different generators: The Celon electrodes were powered by a CelonPOWER generator (470 kHz; Olympus Corporation). The Habib ${ }^{\mathrm{TM}}$ EndoHPB probe was operated by a Vio 300D generator $(450 \mathrm{kHz}$; Erbe Elektromedizin $\mathrm{GmbH}$ ). The Habib ${ }^{\mathrm{TM}}$ VesOpen was powered by a KLS Martin Maxium generator $(403 \mathrm{kHz}$; KLS Martin Group). Ablations were performed until 'roll off', i.e., automatic termination due to rapidly increasing tissue impedance or until a maximum duration of $10 \mathrm{~min}$. Each ablation was performed in one single power level. For each probe, an empiric range of power settings were selected between 2 and 20 watts (Fig. 2A). A total of 10 ablations were performed per power setting. All ablations and measurements were performed by the author SR. The experimental comparison of EndoHPB using different generators (Erbe and KLS) was performed in the second part of the study and is described below.

Comparison of generators. A total of four generators were compared: Erbe Vio 300D, KLS Martin Maxium, Olympus CelonPOWER and Boston RF3000 $(480 \mathrm{kHz}$; Boston Scientific Corporation). All generators were connected to the $\mathrm{Habib}^{\mathrm{TM}}$ EndoHPB probe using a custom-made connector when necessary. The wire length was kept similar in each setup. In the case of the Boston RF3000 generator, the four ground pins were connected to one electrode of the RF probe. The generator setup of coagulation grade for CelonPower is not alterable. The Erbe and KLS Martin generator were used in the basic setting. All ablations and measurements of the comparison of generators were performed the author AJ.

Measurements. The bright coagulation zone was measured in two directions: Lesion length along the axis of the probe and lesion width perpendicular to the longitudinal axis. The results are presented as the mean \pm standard deviation for descriptive purposes. To prevent bias, all data of probe comparison and generator comparison are presented and discussed separately.
Statistical analyses. Statistical analyses were performed using SPSS $^{\circledR}$ (version 27; IBM). Univariate ANOVA was employed to compare the maximum diameter setting of each probe. Spearman's rank correlation coefficients were calculated between lesion width/length and power/ablation time. Using univariate ANOVA, generators were compared at each power setting. Multivariate ANOVA was used to compare power settings and different generators. Bonferroni correction was used as the post hoc test for univariate and multivariate ANOVA. A value $\mathrm{P}<0.05$ was considered to indicate a statistically significant difference. To compare individual probe characteristics independently to the generator, a standardizing factor was calculated for the Boston, KLS and Olympus generators in association with the Erbe generator (Table II). For each power step, the mean ablation zone widths were divided by this factor (Celon probes/Olympus generator, VesOpen probe/KLS generator).

\section{Results}

Ablation catheters. The dependence of the size of the coagulation zone on the power settings differed between the probes (Fig. 2A and C). The measurements of coagulation zone length are not presented due to less distinct differences (data not shown).

Maximum lesion size. There were significant differences in maximum lesion width between the different probes (univariate ANOVA: $\mathrm{P}<0.001$, Fig. $2 \mathrm{~A}$ ): $\mathrm{Habib}^{\mathrm{TM}}$ EndoHPB, 13 watts (W; $10.3 \pm 1.8 \mathrm{~mm})$; HabibTM VesOpen, $12 \mathrm{~W}(11.3 \pm 0.6 \mathrm{~mm})$; Celon ProCurve micro, $2 \mathrm{~W}(7.9 \pm 2.2 \mathrm{~mm})$; and Celon ProCurve 1200, $10 \mathrm{~W}(9.2 \pm 1.1 \mathrm{~mm})$.

Both Habib ${ }^{\mathrm{TM}}$ probes exhibited a gap in the middle of the ablation area at the lower power settings (Fig. 1B). At high power levels, the Celon probes tended to cause incrustation, which resulted in tissue damage whilst removing the probe. The length of the ablation zone correlated with the active tip length (Rho=0.89; $\mathrm{P}<0.001 ;$ Fig. 3A). A significant negative correlation was observed between the power setting and lesion diameter for the ProCurve micro probe $(\mathrm{Rho}=-0.63$; $\mathrm{P}<0.001$; Fig. 3C); no significant correlation was observed for the EndoHPB probe (Fig. 3E) and a positive correlation was observed for the VesOpen probe ( $\mathrm{Rho}=0.63, \mathrm{P}<0.001$; Fig. 3 F) and the ProCurve 1200 probe ( $\mathrm{Rho}=0.37, \mathrm{P}=0.005$; Fig. 3D). At 8 and at $10 \mathrm{~W}$, differences in lesion width were not statistically significant between the EndoHPB, VesOpen and ProCurve 1200 probes. There was a negative correlation between the power setting and ablation time (Rho $=-0.39$ to -0.90 ; P $\leq 0.003$; Fig. 3B). The ablation time was dependent on the generator; at low power settings, the KLS-Generator exhibited no 'roll off'.

Power generators. Ablation zone widths in the bovine liver model differed significantly between the generators (in multivariate ANOVA of the four generators at $6 \mathrm{~W}, 8 \mathrm{~W}, 10 \mathrm{~W}$ and $12 \mathrm{~W}$, and in univariate ANOVA of the four generators at $12 \mathrm{~W}$ : P<0.001; Fig. 2B and Table II). For the KLS generator, the maximum ablation zone widths were $16.8 \pm 1.8 \mathrm{~mm}$ at $10 \mathrm{~W}$. At standard settings with monopolar configuration, the ablation zone width for the Boston generator was $14.3 \pm 1.9 \mathrm{~mm}$ at 
Table I. Technical overview of the different endoluminal RFA catheters.

\begin{tabular}{|c|c|c|c|c|c|c|c|}
\hline RFA catheter & Generator $^{\mathrm{a}}$ & Diameter & Insulation $^{\mathrm{b}}$ & $\begin{array}{c}\text { Length of } \\
\text { active electrode }\end{array}$ & $\begin{array}{l}\text { Active tip } \\
\text { length }\end{array}$ & $\begin{array}{l}\text { Catheter } \\
\text { length }\end{array}$ & $\begin{array}{c}\text { Wire } \\
\text { channel }\end{array}$ \\
\hline Habib $^{\text {TM }}$ EndoHPB & Erbe & $2.7 \mathrm{~mm}$ & $8 \mathrm{~mm}$ & $8 \mathrm{~mm}$ & $24 \mathrm{~mm}$ & $180 \mathrm{~cm}$ & $0.90 \mathrm{~mm}$ \\
\hline Habib $^{\mathrm{TM}}$ VesOpen & KLS & $1.7 \mathrm{~mm}$ & $6 \mathrm{~mm}$ & $6 \mathrm{~mm}$ & $18 \mathrm{~mm}$ & $120 \mathrm{~cm}$ & $0.35 \mathrm{~mm}$ \\
\hline Celon ProCurve micro 300-C09 & Olympus & $1.3 \mathrm{~mm}$ & $1 \mathrm{~mm}$ & $3 \mathrm{~mm}$ & $7 \mathrm{~mm}$ & $30 \mathrm{~cm}$ & None \\
\hline Celon ProCurve 1200 S15 & Olympus & $1.8 \mathrm{~mm}$ & $3 \mathrm{~mm}$ & $4 \mathrm{~mm} / 8 \mathrm{mmc}$ & $15 \mathrm{~mm}$ & $120 \mathrm{~cm}$ & None \\
\hline
\end{tabular}

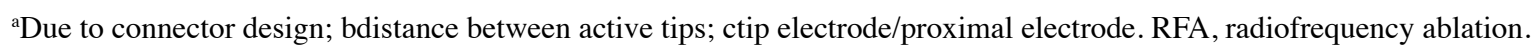

Table II. Overview of ablation effects using different radiofrequency generators at different power settings.

\begin{tabular}{lcrrrr}
\hline & \multicolumn{5}{c}{ Power setting } \\
\cline { 2 - 6 } $\begin{array}{l}\text { Generator used with } \\
\text { the Habib EndoHPB device }\end{array}$ & \multicolumn{1}{c}{$4 \mathrm{~W}$} & \multicolumn{1}{c}{$6 \mathrm{~W}$} & $8 \mathrm{~W}$ & $10 \mathrm{~W}$ & $12 \mathrm{~W}$ \\
\hline Boston & $14.3 \pm 1.9 / 1.3$ & $11.5 \pm 1.6 / 1.1$ & $10.3 \pm 0.5 / 1.1$ & $10.2 \pm 0.4 / 1.1$ & $10.0 \pm 0.5 / 1.1$ \\
Erbe & $10.7 \pm 0.9 / 1.0$ & $10.5 \pm 0.5 / 1.0$ & $9.2 \pm 0.4 / 1.0$ & $9.1 \pm 0.3 / 1.0$ & $8.9 \pm 0.3 / 1.0$ \\
KLS & $-^{\mathrm{a}}$ & $7.2 \pm 0.9 / 0.7$ & $11.2 \pm 1.0 / 1.2$ & $16.8 \pm 1.7 / 1.8$ & $10.1 \pm 0.3 / 1.1$ \\
Olympus & $12.6 \pm 2.3 / 1.2$ & $12.4 \pm 1.6 / 1.2$ & $12.2 \pm 1.2 / 1.3$ & $10.4 \pm 0.7 / 1.1$ & $10.1 \pm 0.5 / 1.1$ \\
\hline
\end{tabular}

${ }^{a}$ At $4 \mathrm{~W}$ no ablation was achieved. Lesion diameter is presented in $\mathrm{mm} \pm$ standard deviation/factor standardized to Erbe generator used for the data shown in Fig. 2C. W, watts.

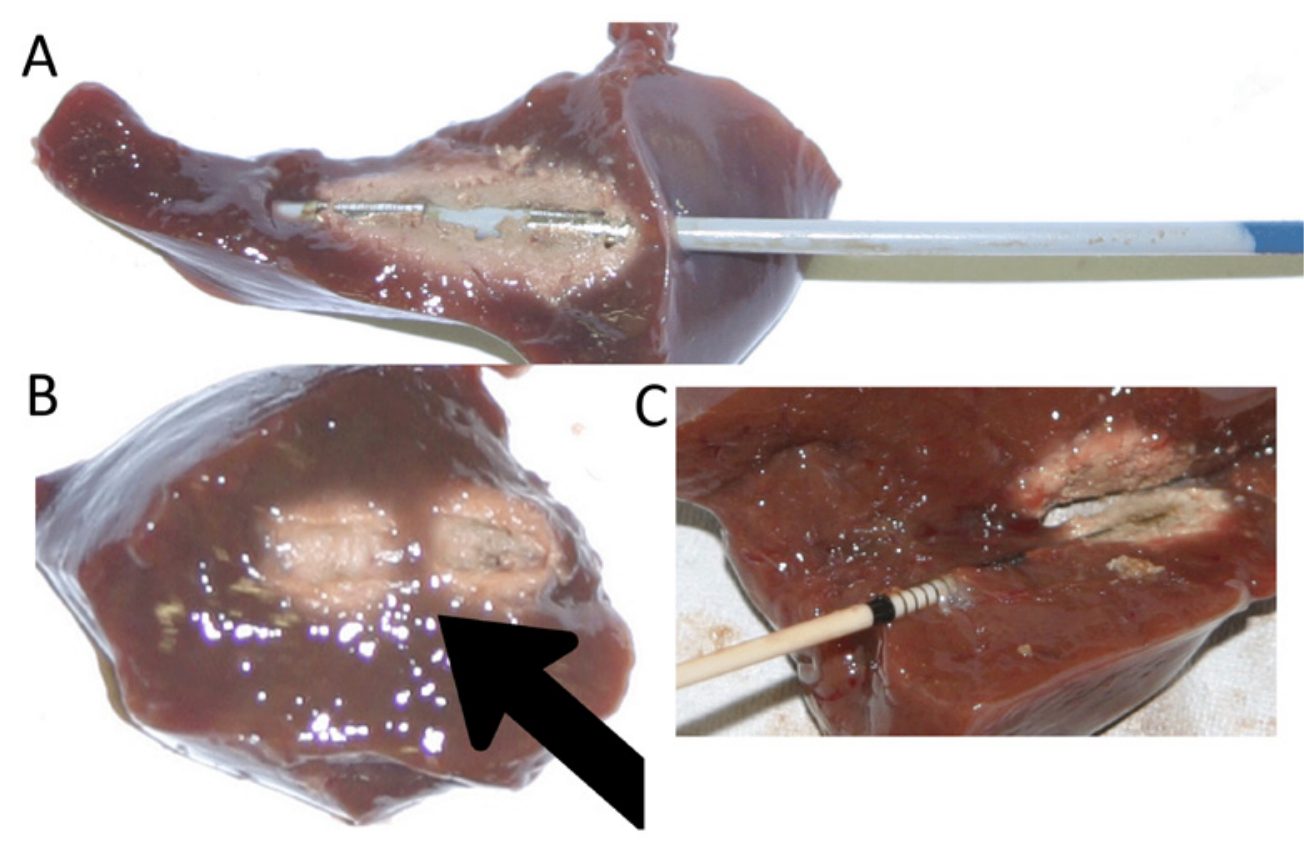

Figure 1. RFA at 10 W: (A) Habib ${ }^{\mathrm{TM}}$ EndoHPB in situ of ablated liver tissue; (B) gap between electrodes following RFA with EndoHPB (arrow); (C) Celon ProCurve 1200 S15. RFA, radiofrequency ablation; W, watts.

$4 \mathrm{~W}$. The use of the Olympus generator at $6 \mathrm{~W}$ resulted in an ablation zone width of $12.4 \pm 1.6 \mathrm{~mm}$. The smallest lesions were induced using the Erbe generator at $4 \mathrm{~W}(10.7 \pm 0.9 \mathrm{~mm})$. For the Boston, Erbe and Olympus generators, a tendency towards smaller lesions was observed at higher power settings. By contrast, the KLS generator produced increasing lesion diameters until $10 \mathrm{~W}$; at $12 \mathrm{~W}$ the lesion diameter decreased.

\section{Discussion}

The endoluminal RFA of malignant bile duct obstruction in combination with stenting is an accepted palliative technique with superior bile duct patency compared to stenting alone (12). Additional to the local tissue detrimental effects of RFA, there is increasing evidence of supplementary RFA-related immunological 

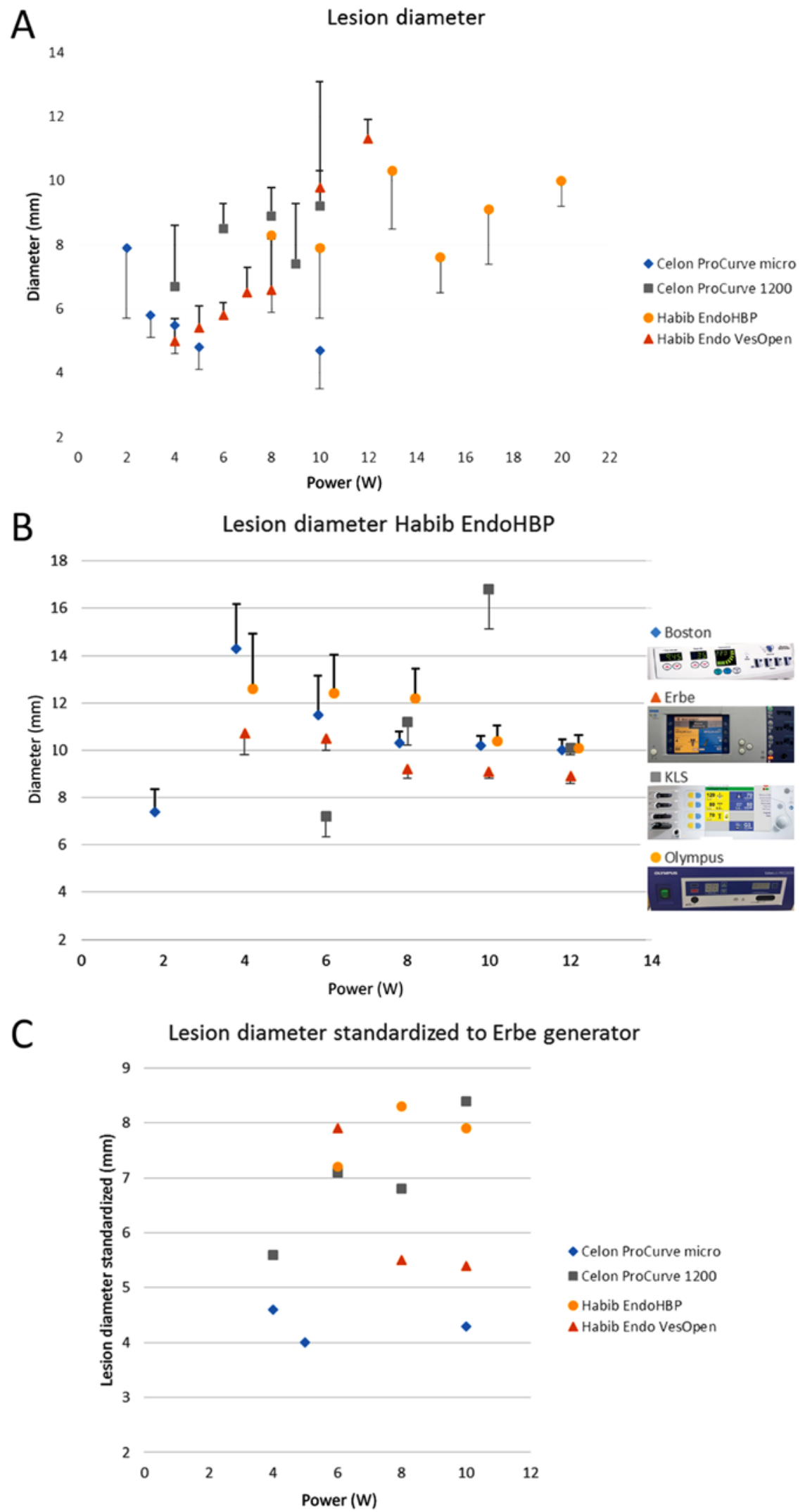

Figure 2. (A) Lesion width using different ablation catheters; Celon catheters with Olympus generator, Habib ${ }^{\mathrm{TM}}$ EndoHPB with Erbe generator and Habib $^{\mathrm{TM}}$ VesOpen with KLS generator. (B) Use of only Habib EndoHPB with four different generators. (C) Standardized results of panel A using the results of panel B and Table II to correct generator differences. Standard deviation is plotted in one direction for reasons of clarity. W, watts.

antitumor effects (18). Due to the relatively rare indication for this technique, there is currently no area-wide experience with endoluminal RFA. Therefore, there is a lack of standardization of these procedures (19). Data published on practical differences between RFA generators and combinations with different catheters are limited, which impedes the implementation of standard protocols. 
A

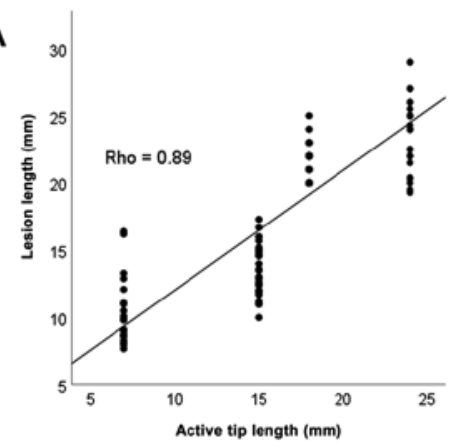

$\mathrm{B}$

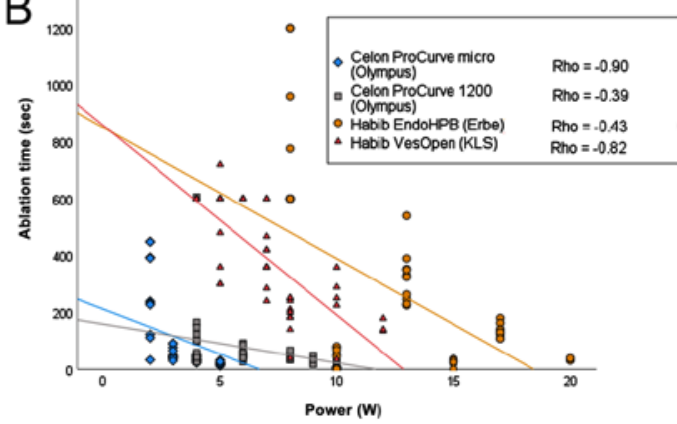

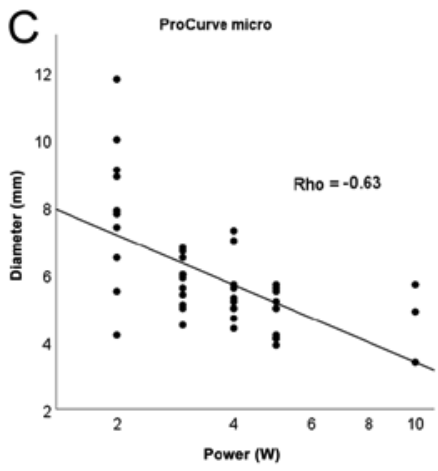
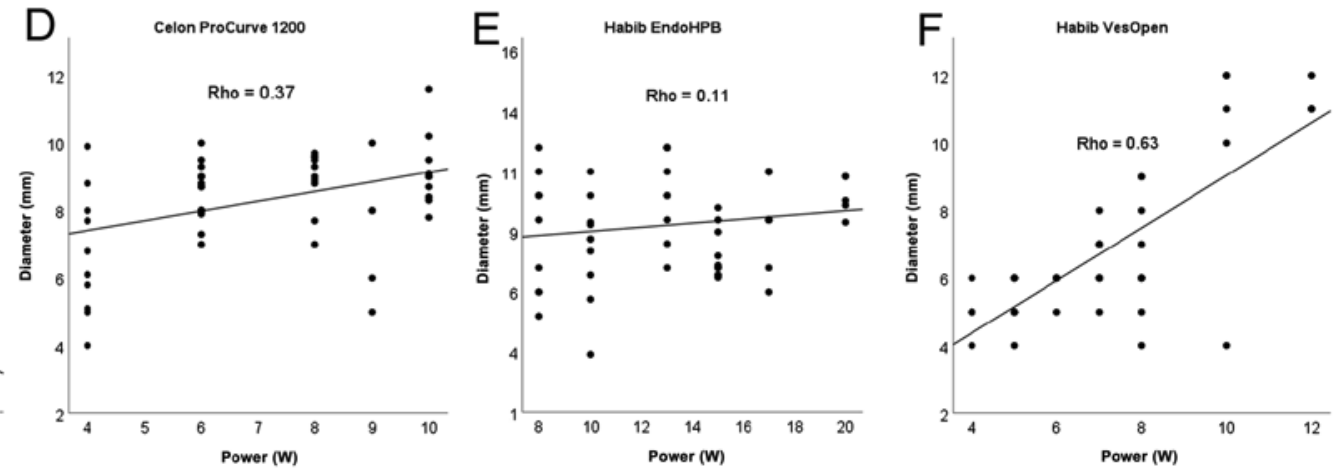

Figure 3. Spearman's correlation analysis of (A) lesion length and active tip length, (B) ablation time and power setting dependent on catheter/generator, and (C-F) lesion diameter and power setting for each tested catheter. Note that some dots are projected onto one another due to millimeter scaling. At higher power levels, only a few measurements were performed due to the defect of the catheter. The scattering in panel A is due to the accumulation of data at each power setting.

Choi et al (20) documented a linear correlation of ablation time and ablation depth using an in vivo swine model. A bipolar electrode was applied for 60,90 and $120 \mathrm{sec}$ at $10 \mathrm{~W}$. In freshly excised human specimens, Atar et al (21) demonstrated similar results at three power settings using a bipolar ablation device. In addition, in an ex vivo porcine liver model, Rustagi et al (19) examined the EUS guided Habib catheter in combination with one single generator at different power settings. For this combination, they defined an ablation time of $90 \mathrm{sec}$ at $10 \mathrm{~W}$ as an optimum. In contrast to the study by Choi et al (20), Rustagi et al (19) documented a saturation kinetics at long ablation times. Moreover, higher wattage did not lead to greater ablation depth. Lesion length was less dependent on power settings.

Although RFA is a relatively robust ablation method, the authors' experience with different power generators and ablation catheters raised the question of practical differences between different combinations. The present study demonstrated that the ablation effect did not only correlate with the catheter design, power setting and ablation time, but was also dependent on the power generator. Knowledge of ablation characteristics of these devices, particularly in different combinations is essential to reduce procedural complications.

Ablation catheters. All tested bipolar catheters created reproducible oval lesions. The observed kinetics of the ablation depth were in line with the findings from the study by Rustagi et al (19). At higher power levels, the RFA probes tended to cause carbonization, which led to reduced conductivity around the active catheter tip, which in turn limited the ablation efficacy. The incrustation of the active tip bears the risk of tissue injury whilst removing the probe. This effect was more pronounced in devices with short distances between the active electrodes. Devices with greater distance between the electrodes tend to leave a central gap in the ablation area at lower power settings, which may be prevented by multiple ablations in axis of the probe. The recently introduced ELRA $^{\mathrm{TM}}$ catheter with four electrodes, which was not tested in the present study, may overcome this issue (22).

The power consumption of the electrodes in the bovine liver model in the present study was in line with in vivo data from clinical reports $(3,4)$. Power settings and ablation time should be selected individually in order to avoid complications, such as damage to surrounding structures (3). Different ablation probes may additionally assist in the management of individual tumor stenosis of the biliary or vascular tree of the liver.

Power generators. Even though it is known empirically in clinical practice, only limited data have been published on the differences in output between radiofrequency generators (23). Technical key data and the operation of generators are very similar. Nonetheless, the present study observed relevant differences in the size of the induced lesions of up to $84 \%$, ranging from $9 \mathrm{~mm}$ to $17 \mathrm{~mm}$ lesion width at $10 \mathrm{~W}$ (Table II). By using the same ablation catheter, it was possible to compare the different generators directly in the current experimental setting.

In the future, other techniques, such as microwave ablation and irreversible electroporation may prove to be interesting candidates for endoluminal tumor therapy $(24,25)$. Given the fact that the integration of endoluminal RFA into clinical practice required decades to achieve, immense efforts are warranted for standards to be set in this field. 
The present study had some limitations which are as follows: i) The real-life conclusions of the present study are limited due to the ex vivo concept, as the effects of perfusion are not reflected. However, the set up used herein aimed to demonstrate physical principles regarding the combination of different ablation probes and power generators. Therefore, an ex vivo approach is highly reproducible as there are no variable confounding perfusion effects. Furthermore, the vast number of repeated ablations render an in vivo approach less practical. ii) The repeated use of the ablation probes may have led to confounding results. The lower power settings were measured at the beginning of the experiment; thus, the effects caused by the fusion of the electrodes should be neglectable. iii) For technical reasons, ablation probes that are powered by different generators were compared. This set up led to the approach of comparing generators. 'Generator correction' by standardization may aid in the characterization of the probes.

In conclusion, the present study demonstrates that the design of RFA catheters and technical properties of the RFA generators have an essential impact on ablation efficacy. The interventional team should operate with constant combinations of equipment. Higher power settings do not automatically result in larger ablation volumes and may cause detrimental effects due to carbonization.

\section{Acknowledgements}

Not applicable.

\section{Funding}

No funding was received.

\section{Availability of data and materials}

The datasets used and/or analyzed during the current study are available from the corresponding author on reasonable request.

\section{Authors' contributions}

SR and AJ performed the experiments. SR, AJ and PM were involved in the writing of the manuscript and data presentation, with the support and input of HUK. AHM was involved in the conception of the study. AHM, PM and HUK supervised the study. SR and AJ confirm the authenticity of all the raw data. All authors have read and approved the final manuscript.

\section{Ethics approval and consent to participate}

Freshly excised bovine liver was obtained from the food sector. Therefore, no ethics approval was required.

\section{Patient consent for publication}

Not applicable.

\section{Competing interests}

The authors declare that they have no competing interests.

\section{References}

1. Bridgewater J, Galle PR, Khan SA, Llovet JM, Park JW, Patel T, Pawlik TM and Gores GJ: Guidelines for the diagnosis and management of intrahepatic cholangiocarcinoma. J Hepatol 60: 1268-1289, 2014

2. Navaneethan U, Thosani N, Goodman A, Manfredi M, Pannala R, Parsi MA, Smith ZL, Sullivan SA, Banerjee S and Maple JT; ASGE Technology Committee: Radiofrequency ablation devices. VideoGIE 2: 252-259, 2017.

3. Strand DS, Cosgrove ND, Patrie JT, Cox DG, Bauer TW, Adams RB, Mann JA, Sauer BG, Shami VM and Wang AY: ERCP-directed radiofrequency ablation and photodynamic therapy are associated with comparable survival in the treatment of unresectable cholangiocarcinoma. Gastrointest Endosc 80: 794-804, 2014

4. Dolak W, Schreiber F, Schwaighofer H, Gschwantler M, Plieschnegger W, Ziachehabi A, Mayer A, Kramer L, Kopecky A, Schrutka-Kölbl C, et al; Austrian Biliary RFA Study Group: Endoscopic radiofrequency ablation for malignant biliary obstruction: A nationwide retrospective study of 84 consecutive applications. Surg Endosc 28: 854-860, 2014.

5. Dutta AK, Basavaraju U, Sales L and Leeds JS: Radiofrequency ablation for management of malignant biliary obstruction: A single-center experience and review of the literature. Expert Rev Gastroenterol Hepatol 11: 779-784, 2017.

6. Mizandari M, Kumar J, Pai M, Chikovani T, Azrumelashvili T, Reccia I and Habib N: Interventional radiofrequency ablation: A promising therapeutic modality in the management of malignant biliary and pancreatic duct obstruction. J Cancer 9: 629-637, 2018.

7. Yang J, Wang J, Zhou H, Zhou Y, Wang Y, Jin H, Lou Q and Zhang X: Efficacy and safety of endoscopic radiofrequency ablation for unresectable extrahepatic cholangiocarcinoma: A randomized trial. Endoscopy 50: 751-760, 2018.

8. Andrasina T, Rohan T, Panek J, Kovalcikova P, Kunovsky L, Ostrizkova L and Valek V: The combination of endoluminal radiofrequency ablation and metal stent implantation for the treatment of malignant biliary stenosis - Randomized study. Eur J Radiol 142: 109830, 2021.

9. Camus M,Napoléon B, Vienne A,Le Rhun M,Leblanc S, Barret M, Chaussade S, Robin F, Kaddour N and Prat F: Efficacy and safety of endobiliary radiofrequency ablation for the eradication of residual neoplasia after endoscopic papillectomy: A multicenter prospective study. Gastrointest Endosc 88: 511-518, 2018.

10. So H, Oh CH, Song TJ, Lee HW, Hwang JS, Ko SW, Oh D, Park DH, Lee SS, Seo DW, et al: Feasibility and safety of endoluminal radiofrequency ablation as a rescue treatment for bilateral metal stent obstruction due to tumor ingrowth in the Hilum: A Pilot Study. J Clin Med 10: 952, 2021.

11. Hu B, Sun B, Gao DJ, Wu J, Ye X, Xia MX and Wang TT: Initial experience of ERCP-guided radiofrequency ablation as the primary therapy for inoperable ampullary carcinomas. Dig Dis Sci 65: 1453-1459, 2020.

12. Gao DJ, Yang JF, Ma SR, Wu J, Wang TT, Jin HB, Xia MX, Zhang YC, Shen HZ, Ye X, et al: Endoscopic radiofrequency ablation plus plastic stent placement versus stent placement alone for unresectable extrahepatic biliary cancer: A multicenter randomized controlled trial. Gastrointest Endosc 94: 91-100.e2, 2021.

13. Mizandari M, Ao G, Zhang Y, Feng X, Shen Q, Chen M, Lau W, Nicholls J, Jiao L and Habib N: Novel percutaneous radiofrequency ablation of portal vein tumor thrombus: Safety and feasibility. Cardiovasc Intervent Radiol 36: 245-248, 2013.

14. Suzuki H, Sekine Y, Saito K, Nakajima T, Sakairi Y, Yoshida S and Yoshino I: Innovative technique of transbronchial radiofrequency ablation for intrapulmonary tumors: A preliminary study in a rabbit model. J Bronchology Interv Pulmonol 18: 211-217, 2011.

15. Sommer CM, Lemm G, Hohenstein E, Bellemann N, Stampfl U, Goezen AS, Rassweiler J, Kauczor HU, Radeleff BA and Pereira PL: CT-guided bipolar and multipolar radiofrequency ablation (RF ablation) of renal cell carcinoma: Specific technical aspects and clinical results. Cardiovasc Intervent Radiol 36: 731-737, 2013.

16. Li TF, Huang GH, Li Z, Hao CF, Ren JZ, Duan XH, Zhang K, Chen C, Han XW, Jiao DC, et al: Percutaneous transhepatic cholangiography and intraductal radiofrequency ablation combined with biliary stent placement for malignant biliary obstruction. J Vasc Interv Radiol 26: 715-721, 2015. 
17. Itoi $\mathrm{T}$, Isayama $\mathrm{H}$, Sofuni $\mathrm{A}$, Itokawa $\mathrm{F}$, Tamura $\mathrm{M}$, Watanabe $\mathrm{Y}$, Moriyasu F, Kahaleh M, Habib N, Nagao T, et al: Evaluation of effects of a novel endoscopically applied radiofrequency ablation biliary catheter using an ex-vivo pig liver. J Hepatobiliary Pancreat Sci 19: 543-547, 2012.

18. den Brok MH, Sutmuller RP, van der Voort R, Bennink EJ, Figdor CG, Ruers TJ and Adema GJ: In situ tumor ablation creates an antigen source for the generation of antitumor immunity. Cancer Res 64: 4024-4029, 2004.

19. Rustagi T, Gleeson FC, Abu Dayyeh BK, Topazian MD and Levy MJ: Evaluation of effects of radiofrequency ablation of ex vivo liver using the 1-Fr wire electrode. J Clin Gastroenterol 52: 168-171, 2018.

20. Choi HH, Shin OR, Kim HK, Jeon BS, Park YW, Kim SW, Kim SS, Chae HS and Lee SV: Efficacy of endobiliary radiofrequency ablation using a novel endoluminal radiofrequency ablation catheter in a swine model. J Invest Surg 32: 731-737, 2019.

21. Atar M, Kadayifci A, Daglilar E, Hagen C, Fernandez-Del CastilloC and Brugge WR: Ex vivo human bile duct radiofrequency ablation with a bipolar catheter. Surg Endosc 32: 2808-2813, 2018.
22. Laleman W, van der Merwe S, Verbeke L, Vanbeckevoort D, Aerts R, Prenen H, Van Cutsem E and Verslype C: A new intraductal radiofrequency ablation device for inoperable biliopancreatic tumors complicated by obstructive jaundice: The IGNITE-1 study. Endoscopy 49: 977-982, 2017.

23. Rathke H, Hamm B, Güttler F, Rathke J, Rump J, Teichgräber U and de Bucourt M: Comparison of four radiofrequency ablation systems at two target volumes in an ex vivo bovine liver model. Diagn Interv Radiol 20: 251-258, 2014.

24. Lee KW, Lee JM, Choi HS, Kim ES, Keum B, Seo YS, Jeen YT, Um SH, Lee HS, Chun HJ, et al: Novel ablation therapy using endoscopic irreversible electroporation in the bile duct: A pilot animal study. Clin Endosc 54: 413-419, 2021

25. Uyanık SA, Öğüşlü U, Yılmaz B, Çevik H, Atlı E and Gümüş B: Percutaneous intraductal microwave ablation of malignant biliary strictures: Initial experience. AJR Am J Roentgenol 215: 753-759, 2020. International (CC BY-NC-ND 4.0) License. 